\title{
EL PERSILES EN EL SIGLO XVIII (LA PEREGRINACIÓN, EL VIAJE ILUSTRADO Y LA ESTRUCTURA BIZANTINA EN LAS OBRAS NARRATIVAS DE ZAVALA Y ZAMORA)
}

No me siento ligado a nada salvo a la desprestigiada herencia de Cervantes. (MILAN KunderA, El arte de la novela)

Per a l'Esther

Pese a los abundantes y espléndidos trabajos que la crítica cervantina de hoy nos ofrece, todavía hemos de lamentar la falta de atención crítica y el olvido histórico que se comete con el Persiles de Cervantes. Básicamente los estudios sobre la novela póstuma del escritor complutense - claro está, con algunas notabilísimas excepciones- adolecen, a mi modo de ver, de no considerar la enorme significación de ésta en la historia de la narrativa española de la Edad de Oro. Y hago esta afirmación, no sólo pensando en la importancia del Persiles en la configuración del género bizantino, modelo narrativo que, como se encargó de demostrar hace ya mucho tiempo el profesor Antonio Vilanova en un trabajo fundamental $^{1}$, se convirtió en el paradigma de la novela de la Contrarreforma en España. Pienso, sobre todo, en el lugar que ocupa en la historia de la novela de entretenimiento, de aventuras e imaginación, considerándola en toda su amplitud, desde la Edad Media hasta los albores de la novela moderna.

Como demostré en un trabajo anterior, el Persiles de Cervantes recoge la herencia de la tradición narrativa caballeresca y transforma ideológica y estéticamente sus elementos constituyentes, imbuyéndolos en un espíritu cristiano y estoico profundamente moralizador, adaptándolos, en suma, a las necesidades ideológicas y

1 «El peregrino andante en el Persiles de Cervantes $\nsim$, Boletín de la Real Academia de Buenas Letras de Barcelona, XXII, 1947, pp. 97-159; ahora en Erasmo y Cervantes, Barcelona, Lumen, 1989, pp. 326-409. 
estéticas de la Contrarreforma ${ }^{2}$. En este sentido - y resumo aquí la tesis que defendí entonces y todavía defiendo-, soy de la opinión que Cervantes escribió el Persiles con la decidida voluntad de ofrecer al público de su tiempo un nuevo modelo de novela de aventuras que renovara y mejorara la caduca y anacrónica narrativa de caballerías desarrollada en Castilla a lo largo del siglo XVI. En este sentido, la novela póstuma de Cervantes, publicada en las prensas madrileñas de Juan de la Cuesta en 1617, vendría a cubrir el vacío en la novela de entretenimiento causado por la parodia quijotesca, y sería su respuesta a las preguntas causadas por ese vacío ${ }^{3}$.

Me propongo ahora, en la misma línea, continuar mi investigación sobre el valor fundamental que, a mi modo de ver, tiene el Persiles en la historia de la narrativa española estudiando algunos aspectos de su recepción y fortuna literaria durante el siglo XVIII. $\mathrm{Si}$ bien es sabido que la herencia cervantina, en lo que atañe a su inmortal creación de la primera novela moderna mundial, no es leída e interpretada en todas sus posibilidades por nuestros intelectuales y narradores del Siglo de las Luces, no debemos por ello pensar que el Persiles, la novela en la que nuestro escritor cifró sus ansias de inmortalidad, cayera en el olvido tras su publicación. La novela, como cima del modelo narrativo bizantino, novela de amor y de aventuras cristianizada, fue ampliamente leída y considerada, no ya solamente durante todo el siglo XVII, sino también durante todo el XVIII, llegando a percibirse sus ecos y las huellas que su

2 David ORdóñez GaRcia, Aventura y Contrarreforma: el "Persiles" de Cervantes $y$ los libros de caballerias, Premio de Ensayo sobre Filología Cervantina de la Sociedad Cervantina, Madrid (inédito). La idea que animó mi estudio no era completamente nueva: además del trabajo del profesor VILANOVA, FRANCISCO LÓPEZ ESTRADA ( $\propto$ Prólogo» a su ed. de HELIODORO, Historia etiópica de los amores de Téagenes y Cariclea, Madrid, RAE, 1954, p. xx) y EmILIO CARILLA [«Cervantes y la novela bizantina (Cervantes y Lope de Vega)», Revista de Filología Española, LI, 1966, pp. 155-167] hacen unas tímidas referencias al respecto. DANIEL EISENBERG [ CCervantes y Tasso vueltos a examinar» (1984), ahora en Estudios cervantinos, Barcelona, Sirmio, 1991, pp. 37-56] es un poco más explícito: aél creía que, purificando el libro de caballerías, podía escribir una obra de la talla de las de Homero o Virgilio» (p. 43, nota 16). Vid. también, del mismo autor, «El Bernardo de Cervantes fue su libro de caballerias», Anales Cervantinos, XXI, 1983, pp. 103-117.

3 Creo que son claves las siguientes palabras del capítulo 48 de la primera parte del Quijote, donde el cura, en esa jugosa conversación sobre literatura con el canónigo de Toledo, afirma: $* Y$ si se diese cargo a otro, o a este mismo, que examinase los libros de caballerías que de nuevo se compusiesen, sin duda podrfan salir algunos con la perfección que vuestra merced ha dicho, enriqueciendo nuestra lengua del agradable y precioso tesoro de la elocuencia, dando ocasión que los libros viejos se escureciesen a la luz de los nuevos que saliesen, para honesto pasatiempo, no solamente de los ociosos, sino de los más ocupados, pues no es posible que esté continuo el arco armado, ni la condición y flaqueza humana se pueda sustentar sin anguna lícita recreación» (ed. Martín de Riquer, Barcelona, Círculo de Lectores, 1989, I, p. 610; el subrayado es mí). 
recepción dejó en el renacimiento de la narrativa que se produjo en España hacia 1780. En este sentido, señalaré las influencias que dejaron las aventuras de Persiles y Sigismunda en la novela del siglo ilustrado, centrándome básicamente en la obra narrativa de Gaspar Zavala -Oderay (1804) y La Eumenia (1805)-, recientemente reeditada por el profesor Guillermo Carnero (Universidad de Alicante). Con ello sólo pretendo demostrar que la influencia y la importancia de Cervantes en la literatura posterior no sólo se circunscribe a su inmortal Quijote, sino que su papel de figura clave en la historia de la narrativa también se debe a las esperanzas que el escritor complutense depositó en su novela última.

\section{II}

Lo primero que cabe preguntarnos es si el Persiles -obra de imaginación, aventura y ensueño- interesó a los hombres del siglo ilustrado, el siglo de la razón y del peso de la preceptiva, del ceñirse a unas reglas académicas en la temática y la composición de la obra literaria. Y después, interrogarnos sobre las razones que suscitaron ese interés. En definitiva, investigar a grandes trazos la recepción de la novela póstuma de Cervantes durante el siglo XVIII.

Treinta y siete veces fue reeditado el Quijote a lo largo del siglo ${ }^{4}$. A la luz de su lectura e interpretación por los novelistas ilustrados debemos el cultivo de la novela durante esa centuria, entendida como «una sátira, la más feliz que hasta hoy se ha escrito contra todo género de gentes" ${ }^{5}, \mathrm{y}$, por lo tanto, como instrumento de reprensión de vicios y crítica de costumbres contemporáneas. Pero, en contra de lo que pudiera parecer a primera vista, el Persiles también interesó a los hombres del xVIII. Tras seis ediciones de salida (1617), siguen las de 1618,1619 y 1625, y la última edición que se hizo en el Seiscientos data de 1629; sólo noventa años más tarde vuelve a reeditarla el impresor Juan Sanz de Madrid (1719). A partir de entonces las ediciones se suceden ${ }^{6}$ : Barcelona, 1724; Madrid, Pedro José Alonso y Padilla, $1728^{7}$; Barcelona, Pablo Campins,

4 Francisco Aguilar PINAal, «Cervantes en el siglo XVIII», Anales Cervantinos, XXI, 1983, p. 154.

5 GRegorio Mayans y Siscar, Vida de Miguel de Cervantes Saavedra (1737), ed. Antonio Mestre, Madrid, Espasa-Calpe, 1972, p. 127.

- José SIMón DfAz, Bibliografía de la literatura española, Madrid, CSIC, VIII, 1970, pp. 126-130.

7 JoAquin Álvarez Barrientos sefiala que «la oferta de Padilla es toda ella de novelas españolas del siglo XVII, aunque hay también traducciones de novelas bizantinas» (La novela del siglo XVIII, Madrid, Júcar, 1991, p. 38). Estudia su catálogo como muestra de lo que se leía durante la primera mitad del siglo. 
1734; Barcelona, Juan Nadal, 1760 y 1768; Madrid, Sancha, 1781 ; Madrid, Fermín Villalpando, 1799; Madrid, Sancha, 1802, y Madrid, Viuda de Ibarra, 1805. Como vemos, cinco veces se reedita el Persiles hasta la fecha de 1780 , que se toma habitualmente como punto de partida de un renacimiento en el cultivo novelístico merced a la aparición de unos narradores de singular valía. Desde entonces y hasta 1805, cuatro veces. Ello demuestra que la novela póstuma de Cervantes es leída con gran interés durante toda la centuria -las reediciones se suceden a intervalos de tiempo más o menos regulares-, y su recepción es especialmente tupida o intensa durante el período 1780-1808, que son los años finales del siglo que me interesan, pues en él tiene lugar la actividad narrativa de Gaspar Zavala: intervalos de sólo tres años en el cambio de siglo $(1799,1802$ y 1805). Magisterio excepcional el del Persiles, pues, como veremos, no sólo es, como la obra toda cervantina, un modelo de pureza y casticismo lingüístico a imitar - frente a la avalancha de novelas extranjerizantes y traducciones-, sino que también funcionará como paradigma del género bizantino de amor y de aventuras, el cual seguirá cultivándose durante todo el Dieciocho ${ }^{9}$.

La prosa narrativa del siglo XvIII puede agruparse en dos tendencias: una primera, mera continuación e imitación de las corrientes narrativas del Seiscientos, y una segunda que, partiendo de los géneros narrativos ya existentes, se sitúa claramente en unos caminos de renovación que conducirían a la novela moderna. Renovación temática, de la mano del realismo, por un lado, es decir, de la observación de las costumbres y los problemas de la realidad contemporánea, y por otro, de la mano de la filosofía sensista, que llevará a los narradores a profundizar en los estados anímicos de los personajes, y que tendrá importantes implicaciones estructurales, porque se plantearán nuevos modos de representarlos en los relatos. Las dos novelas de Zavala se inscriben en la segunda tendencia, la renovadora, aunque, como pretendo demostrar, el escritor burgalés parte de unos esquemas narrativos que demuestran la pervivencia de algunos elementos estructurales y temáticos procedentes de la novela bizantina de la Edad de Oro, y más concreta-

8 «La edición más correcta que hasta entonces se había publicado. También es la más bella en la parte material, que ofrece un acabado gusto tipográfico... Reálzala 8 láminas y 4 vifietas dibujos de Ximeno y de Carnicero, finalmente grabadas por Selma» (SIMON DIAZ, op. cit., p. 129).

9 No olvidemos que la Historia etiópica de Heliodoro se reeditó en 1787, en la traducción de Fernando de Mena, lo cual demuestra el interés que existía en el fin de siglo por el modelo narrativo de amor y de aventuras (LOPEZ ESTRADA, op. cit., p. xvii). 
mente, del Persiles de Cervantes como modelo y paradigma a imitar de dicho género ${ }^{10}$.

No insistiré demasiado en la importancia de la tradición y en la conciencia de género, ancilares en la producción literaria hasta el Romanticismo. Baste señalar que el novelista - como el poeta, como el dramaturgo- escribe su obra teniendo en cuenta una tradición literaria anterior y se ciñe a los caracteres que el género le marca. Se escribe la novela en función de esos caracteres que permiten al lector del momento reconocerla dentro de los límites de ese género y satisfacer así sus expectativas estéticas ${ }^{11}$. Eso sucede en el siglo XVIII; a lo largo de toda la centuria vamos a encontrar una serie de obras escritas bajo la sombra del modelo bizantino de amor y aventuras ${ }^{12}$.

En la llamada "época renovadora" (1780-1808), debemos destacar tres importantes novelas que se inscriben en el marco del género de amor y aventuras cuyo paradigma es Cervantes. La primera es $E l$ Valdemaro, de Vicente Martínez Colomer (1792), autor también de una Nueva colección de novelas ejemplares (1790), entre las que me interesa destacar La Dorinda y El hallazgo, "relatos fantásticos, exóticos, de aventuras» ${ }^{13}$. Las "novedades» de las que habla Ferreras no son tales si tenemos presente el modelo de Heliodoro y de Cervantes, aunque muchos de sus elementos puedan parecerlo si consideramos la evolución de toda esta novelística hacia el Romanticismo ${ }^{14}$. No me cabe ninguna duda de que el modelo bizantino de amor y aventuras

10 Los estudiosos del género bizantino, como Emilio Carilla (op. cit., p. 166), JUAN BAUTISTA AVALLE-ARCE ( $\propto$ Introducción biográfica y crítica» a su ed. de LOPE DE VEGA, El peregrino en su patria, Madrid, Castalia, 1973, pp. 28-31) y ANTONIO CRUZ CASADO, de manera más explícita («Una revisión del desenlace del Persiles», VV. AA., Actas del II Coloquio de la Asociación Internacional de Cervantistas, Barcelona, Anthropos, 1991, pp. 719-726) señala que «encontramos en el panorama de los libros de aventuras peregrinas dos paradigmas que tienen sucesivos cultivadores: el lopesco y el cervantino» (cito a este último, p. 724).

1 Vid. HANS ROBERT JAUSS, Alteritd e modernitd della letteratura medievale (1977), Turín, Bollati Boringheri, 1989, pp. 219-256.

${ }_{12}$ "Los autores se ocupan del presente utilizando estructuras al menos prestigiadas por su antigüedad, o por su valor como medios moralizantes» (ÁLVAREZ BARRIENTOS, op. cit., p. 42). Sobre la pervivencia del modelo bizantino -en su doble paradigma, el lopesco y el cervantino- durante los siglos XVII y XVIII, vid. la lista de autores y obras que ofrece ANTONIO CRUZ CASADo (op. cit., pp. 724-725), aunque Álvarez BARRIENTOS es mucho más exhaustivo. En un reciente análisis, JAVIER GonzAlez ROVIRA ha señalado que «la última etapa de la novela bizantina es la que marca la desaparición del género, no tanto por la ausencia de obras como por la utilización de la estructura de la novela clásica como marco para la interpolación de materiales heterogéneos que acaban por desvirtuar el concepto mismo de novela» (La novela bizantina de la Edad de Oro, Madrid, Gredos, 1996, p. 329). Ya en el siglo XVIII, «la novela bizantina evoluciona hacia la mera narración de aventuras» (ibidem, p. 392).

13 JUAN IgNACIO FerReraS, La novela en el siglo XVIII, Madrid, Taurus, 1987, p. 53.

14 «Ante todo, la peripecia se complica, hay naufragios, batallas, encuentros y pérdidas, hay también suicidios como en La Dorinda, amores imposibles y amores 
cobró actualidad y nueva significación con la entrada en España de la filosofía sensista y el modelo de la novela sentimental y lacrimosa ${ }^{15}$. Alvarez Barrientos hace, a mi modo de ver, una lectura más acertada de la temática y la estructura de $E l$ Valdemaro: "Vicente Martínez Colomer se apoya en dos puntales principalmente, uno estético -el Persiles de Cervantes-y otro ético - su didactismo". Observando el argumento de la obra, su vinculación con el paradigma cervantino se hace innegable, pudiéndose hablar incluso de «excesiva fidelidad al modelo cervantinon. Muy interesante me parece la observación de que «el ambiente ideal, de escenarios tormentosos y nocturnos, donde también asistimos a lances propios de la novela de caballerías, es utilizado por Martínez Colomer para darnos un discurso ilustrado» ${ }^{16}$. La actualización o adaptación del género a los problemas contemporáneos, revistiéndolo de las ideas ilustradas, es uno de los puntos clave del interés de los narradores dieciochistas por la novela bizantina. Se mantienen los rasgos básicos que permiten reconocer a la obra en el marco que dicta la tradición del género, pero a la vez se la reviste de actualidad dando paso a contenidos propios de la sociedad en la que autor y lector se inscriben.

Un paso más en esta actualización dará Antonio Valladares de Sotomayor en La Leandra, larguísima novela publicada en nueve volúmenes (1797-1807) e inacabada, que sigue el esquema bizantino pero con una novedad estructural que afecta a varias instancias narrativas -narrador, distancia, perspectiva, voz...: el formato epistolar, el cual, según Álvarez Barrientos, "oculta un entramado de narraciones que se sostiene sobre la estructura del relato de viajes, al estilo del Persiles pero también el El Valdemaro" ${ }^{17}$. Ello la acerca mucho al modelo de la Pamela de Richardson (1749), la Nouvelle Heloïse de Rousseau (1761) y Les liaisons dangereuses de Choderlos de Laclos (1782), novelas todas ellas ampliamente leídas durante todo el fin de siglo.

El Emperador o las aventuras de un español en Asia, de Jerónimo Martín de Bernardo (1805) «es una extraordinaria novela de

correspondidos, y hay sobre todo, una nueva manera de narrar, más suelta y moderna. El autor maneja muy bien el suspense y posee suficiente técnica como para empezar varias de sus obras in media res, lo que origina como es logico, no sólo una vuelta atrás sino la transformación de varios personajes en narradores (cada personaje cuenta su historia)» (ibidem, p. 54). Todos estos elementos estaban ya en el Persiles.

15 No deja de ser curioso, como afirma López Estrada, que el prólogo de la edición de 1787 de la Historia Etiópica se refiera a esta obra como «romanesca» (op. cit., p. liii).

16 Op. cit., pp. 259, 257 y 259. MARTINEZ COLOMER es también autor de una novela deaventuras titulada Los trabajos de Narciso y Filomena. Según ANTONIO CRUZ CASADO, esta obra «elige al Persiles como modelo inmejorable de ficción narrativa* («El viaje como estructura narrativa: Los trabajos de Narciso y Filomela, de Vicente Martínez Colomer, una novela inédita», Dicenda. Cuadernos de Filologia Hispánica, 7, 1987, p. 311).

17 Op. cit., p. 286. 
aventuras que se desarrolla en Basora" y que se sirve - de nuevode la estructura bizantina ${ }^{18}$. Como vemos, a lo largo de todo el siglo XVIII, y singularmente en los años cruciales del cambio de siglo, el modelo bizantino - avalado por esas tres reediciones del Persiles que se suceden tan rápidamente- cobra nueva actualidad en el marco de la renovación del panorama narrativo que los autores mencionados intentan, y en el que Zavala se sitúa.

Entendida la novela en el siglo XviII como un instrumento al servicio de la moral, como un arma pedagógica a esgrimir contra los vicios y las malas costumbres, no puede sorprendernos la acogida favorable del modelo bizantino durante la centuria. El Persiles de Cervantes, paradigma de la Contrarreforma, presenta un nuevo modelo de héroe, el peregrino andante, dechado de virtudes cristianas, el cual desarrolla una serie de aventuras cuya finalidad no es otra que el perfeccionamiento religioso y el matrimonio con una mujer a la que ha amado dentro de los estrictos límites del amor platónico cristianizado. La novela póstuma de Cervantes consigue un perfecto equilibrio entre el propósito de entretener o deleitar a un público acostumbrado a las narraciones caballerescas, el propósito moralizador acorde con los dictados del Concilio de Trento y su adecuación o acomodación a una preceptiva celosa de los cánones clásicos y que exigía la adscripción a un género narrativo sancionado por la Antigüedad que avalara la suficiencia estética de la obra. Por ello ésta fue la obra en la que Cervantes depositó sus esperanzas de pasar a la inmortalidad literaria: se adecuaba perfectamente a las exigencias estéticas de su tiempo. Me atrevo a decir que los preceptistas del siglo ilustrado no habían variado mucho su punto de vista desde entonces. En su Vida de Miguel de Cervantes (1737), el erudito valenciano Gregorio Mayans y Siscar califica en estos términos el Persiles:

Cervantes dijo que su Persiles y Sigismunda se atrevía a competir con Heliodoro. La mayor alabanza que podemos darle es decir que es cierto. Los amores que refieren son castíssimos, la fecundidad de la invención, maravillosa en tanto grado que, pródigo su ingenio, excedio en la multitud de episodios. Los sucessos son muchos i mui varios. En unos se descubre la imitación de Heliodoro, i de otros mui mejorada; en los demás, campea la novedad. Todos están dispuestos con arte $\mathrm{i}$ bien explicados con circunstancias casi siempre verosímiles. Quanto más se interna el letor en esta obra tanto es mayor el gusto de leerla, siendo el tercero i quarto libro mucho mejores que el primero y el segundo. Los continuos trabajos

18 Ibidem, p. 344. Errónea me parece-como creo haber demostrado hasta ahora basándose en las investigaciones de ÁlVAREZ BARRIENTOS- la afirmación de FERRERAS al hablar de esta novela: «Creo que es importante este título porque en España, en estas fechas, llevamos ya cerca de un siglo sin cultivar la pura novela de aventuras» (op. cit., p. 70). 
llevados en paciencia acaban en descanso sin máquina alguna, porque un hombre como Cervantes sería milagro que acabasse con algún milagro para manifestar la felicidad de su raro ingenio. En las descripciones excedió a Heliodoro. Las déste suelen ser sobrado freqüentes i mui pomposas. Las de Cervantes, a su tiempo i mui naturales. Aventajóle también en el estilo, porque, aunque el de Heliodoro es elegantíssimo, es algo afectado, demasiadamente figurado i más poético de lo que permite la prosa. Defecto también en que cayó también el discreto Fenelón [se refiere al Telémaco]. Pero el de Cervantes es propio, proporcionalmente sublime, modestamente figurado i templadamente poético, en tal qual descripción ${ }^{19}$.

Glosando su exposición, diré que Mayans aplaude el modelo cervantino de amor y de aventuras por haber logrado ese difícil equilibrio entre el deleitar y el enseñar, a la vez que pondera la suficiencia estética de la novela - la invención, el estilo-, reconociendo incluso que:

En suma, esta obra es de mayor invención, artificio i de estilo más sublime que la de Don Quijote de la Mancha. Pero no ha tenido igual aceptación, porque la invención de la Historia de Don Quijote es más popular i contiene personas más graciosas i, como son menos en número, el letor retiene mejor la memoria de las costumbres, hechos i caracteres de cada una. Fuera de esso, el estilo es más natural i tanto más descansado quanto menos sublime ${ }^{20}$.

Interesantísima la razón — de orden sociológico- que argumenta Mayans para explicar el mayor éxito del Quijote: la parodia al viejo modelo ha sido - paradójicamente - mejor acogida por el público y más provechosa para la evolución del género narrativo que el nuevo modelo que Cervantes ofrece como alternativa. Podemos tomar los juicios de Mayans como representativos de la sensibilidad dieciochesca, y éstos se nos revelan en toda su importancia si consideramos que el erudito valenciano, según Pérez Magallón, «acomete el intento de dar forma a lo que podría llamarse una teoría de la novela de corte clasicista" ${ }^{21}$.

Otro ejemplo. En el prólogo-justificación a El Valdemaro, Maŕtínez Colomer insiste en los mismos términos al exponer los requisitos estéticos y morales que debe cumplir la novela:

Placer y utilidad, de aquí los principales caracteres que debe tener una obra para que sea recomendable. El placer puede embriagar el espíritu de los lectores y enajenarlo en sabroso éxtasis, pero siempre dejará vacío

19 Ed. cit., pp. 180-181.

20 Ibidem, p. 181.

21 JESÚS PEREZ MAGALLON, «Una teoría dieciochesca de la novela y algunos conceptos de poética», Anales de Literatura Espartola, 5, 1986-87, p. 358. Vid. también, del mismo autor, «L'estètica en Maians i Siscar», Els Marges, 42, 1990, pp. 100-117. 
el entendimiento; ni la utilidad podrá llenar jamás este vacío cuando se fija en una instrucción seca y áridamente propuesta ${ }^{22}$.

Tengamos en cuenta - antes lo he señalado- que Martínez Colomer se apoya en el modelo cervantino ética y estéticamente. Los mismos presupuestos en los que Cervantes se basa para construir su novela póstuma siguen siendo de actualidad en los años cruciales del cambio de siglo:

Una fábula maravillosa y verosímilmente sostenida, cuyos episodios sean oportunos, bien pintados los caracteres de las personas, vivas y graciosas las descripciones, animadas las narraciones, afectuosas y patéticas las escenas, exacta la elocución y primorosamente ejecutado cuanto se requiere para una obra de esta clase ${ }^{23}$.

El autor reconoce la oportunidad de la novela de aventuras, siempre y cuando de ellas pueda deducir el lector una enseñanza edificante. En Los trabajos de Narciso y Filomela, Martínez Colomer defiende a su modelo en los siguientes términos:

En cuanto al que lleva en la historia, dicen los que lo han leído que no es despreciable, porque ha tomado por modelo al nunca bien alabado Miguel de Cervantes, en su Persiles y Sigismunda, cuya memoria será eterna en la de las gentes ${ }^{24}$.

Siguiendo los dictados de Fernando García Lara, «el punto de partida [para el estudio de los materiales novelescos del siglo XVIII] habrá de ser el de delimitar el alcance y carácter de unos textos que buscan su encaje dentro de una tradición y de unas prácticas que hay que reconstruir" ${ }^{25}$. Se dotan de contenidos nuevos unas formas narrativas ya existentes, a la vez que esos contenidos transforman o hacen evolucionar esas formas. Eso es, en breves palabras, lo que sucede en el siglo XVIII con el modelo bizantino de amor y de aventuras cuyo paradigma es el Persiles. La intentio auctoris y la intentio operis siguen siendo de rigurosa actualidad entre los teóricos y creadores del siglo ilustrado, sólo que los moldes narrativos van a llenarse con temas y problemas propios del momento, actualizándose.

Lo que me propongo a continuación es analizar de qué manera y en qué medida perviven los rasgos estructurales de la novela

22 Vicente Martinez Colomer, El Valdemaro, ed. Guillermo Carnero, Alicante, Instituto de Estudios Juan Gil-Albert, 1985, p. 51. Agradezco al profesor Miguel Ángel Lozano Marco (Universidad de Alicante) su gentileza por enviarme un ejemplar de esta edición.

23 Ibidem.

24 ANTONIO CRUZ CASADO, «El viaje como estructura narrativa...», cit., p. 323.

25 «Materiales novelescos en la primera mitad del siglo XVIII*, Insula, 546, 1992,

p. 13. 
bizantina - cuyo modelo es, en el siglo XVIII, el Persiles-, en La Eumenia y Oderay de Gaspar Zavala y Zamora, estudiando las formas de desarrollo de la acción narrativa y su sentido, con lo que intentaré demostrar la presencia o actualidad del paradigma bizantino en los años aurorales del Romanticismo español centrándome en la obra de este olvidado escritor burgalés.

\section{III}

Definida como "aventura» en las narraciones caballerescas y apoyada en el motivo del viaje, en la traslación del personaje -único elemento que daba unidad a la obra- por diferentes escenarios donde topaba con otros personajes - secundarios- y con situaciones adversas que tenía que afrontar, en la novela bizantina, y más concretamente en el Persiles de Cervantes, el carácter de la acción narrativa se transformará en tan gran medida que ese continuo movimiento del protagonista se llamará "peregrinación»" ${ }^{26}$. La finalidad no será ya la consecución de gloria, fama y honor, sino el perfeccionamiento moral -amoroso y religioso ${ }^{27}$.

En el siglo XVIII el viaje ya no es concebido con un propósito de perfeccionamiento moral, sino de conocimiento o ilustración intelectual. Conocer nuevas realidades humanas, nuevos países, y sobre todo, los hombres que los habitan, sus costumbres y su lengua, en definitiva, obtener de sus experiencias un enriquecimiento para su formación personal. Como ha dicho Gaspar Gómez de la Serna,

26 En el primer capítulo del Quijote, el todavía Alonso Quijano, que se propone ser un caballero andante, concibe su propósito como «irse por todo el mundo con sus armas y caballo a buscar las aventuras y a ejercitarse en todo aquello que él había leído que los caballeros andantes se ejercitaban, deshaciendo todo género de agravio, y poniéndose en ocasiones y peligros donde, acabándolos, cobrase eterno nombre y fama» (ed. cit., I, p. 103). Las aventuras serán llamadas atrabajos» en el Persiles; Periandro declara por primera vez a Arnaldo el motivo de su viaje: $\alpha \mathrm{Mi}$ hermana y yo vamos llevados del destino y la elección a la santa ciudad de Roma, y hasta vernos en ella, parece que no tenemos ser alguno, ni libertad para usar de nuestro albedrío. Si el cielo nos llevare a pisar la santísima tierra y adorar sus reliquias santas, quedaremos en disposición de disponer de nuestras hasta agora impedidas voluntades» (Los trabajos de Persiles y Sigismunda, ed. JUAN BAUTISTA AvAllE-ARCE, Madrid, Castalia, 1987, 2." ed., p. 125). Y, más adelante, Auristela confiesa a su amiga Transila: ${ }^{\circ}$ De tal manera estoy obligada a tener en perpetuo silencio una peregrinación que hago, que hasta darle fin, aunque primero llegue el de la vida, soy forzada a guardarle» (p. 156. Los subrayados son míos).

${ }_{27}$ Para las diferencias y las deudas de la peregrinación cristiana de la novela bizantina con el esquema aventuresco de la novela de caballerías, vid. mi trabajo "La aventura caballeresca y la peregrinación cristiana en el Persiles de Cervantes», Actas del VI Coloquio de la Asociación Internacional de Cervantistas, Barcelona, Anthropos, en prensa. Resumo aquí mis tesis. 
"para lo que viaja el hombre del XviII es para conocer al hombre; no sólo para ver países y tierras". No en vano aparece en esta centuria el género de la literatura de viajes, sin que el viaje esté supeditado a un argumento fictivo: las narraciones responden -0 pretenden responder- a unas vivencias auténticas, a unas experiencias reales de un narrador que siempre se identifica con el escritor, y su escritura se debe al afán de difundir los conocimientos y experiencias entre el público: «se viaja para ilustrarse; mas para emplear esa ilustración en el mejor régimen de la vida pública y privada» ${ }^{28}$. En la novela dieciochesca será muy frecuente el motivo del viaje como hilo conductor de las peripecias, y el yo del personaje que lo protagoniza reconocerá, autoanalizándose, las ventajas que ello supone para el mejoramiento de su espíritu: «El viaje y la isla serán elementos presentes de forma continua en la narrativa dieciochesca: son las excusas para el desarrollo de los análisis interiores de la personalidad, para poner a prueba la educación recibida en una sociedad determinada, educación que resulta inútil en las nuevas circunstancias y sociedad que, a la larga y por contraste, se resuelve en estructura injusta” ${ }^{29}$.

En La Eumenia, los dos viajes que emprenden Termonio y Alfonso en su juventud, sus salidas de los hogares paternos, significan para ellos la ampliación de conocimientos, un enriquecimiento individual con nuevas vivencias en la realidad urbana, de la que ambos acaban desengañados. Pero los viajes que vertebran la acción de La Eumenia responden a la búsqueda de la felicidad, nunca conseguida, como Termonio, o bien perdida, como Eumenia, quien se ha trasladado desde España hasta Bélgica para encontrar a Alfonso:

...un azar me conduxo a vuestra casa; pero no fue el azar quien me sacó de España, donde nací, para traerme a este país, como visteis, en busca de un mortal a quien amo como a vos os reverencio. Es mi esposo, y me ha abandonado por una injusta sospecha ${ }^{30}$.

El amor y la virtud han sido siempre mi Norte, respondió Eumenia; creía hallarle en su patria después de buscarle inútilmente en la mía, y deseaba convencerle con esta sola prueba de la verdad con que le amo y la sinrazón con que obró contra mí dando crédito al odio y a la calumnia (p. 75. El subrayado es mío).

28 Los viajeros de la Ilustración, Madrid, Alianza, 1974, p. 12. Vid. también ANA RODRIGUEZ-FISCHER, «Introducción» a su ed. de LEANDRO FERNANDEZ DE MORATIN, Apuntaciones sueltas de Inglaterra, Barcelona, PPU, 1992, especialmente pp. 59-73.

${ }^{29}$ ÁlVAREZ BARRIENTOS, op. cit., p. 16.

30 GaSPAR ZaVAla Y ZAMORA, Obras narrativas. La Eumenia. Oderay, ed. GuIllermo CARNERO, Barcelona, Sirmio-Quaderns Crema, 1992, p. 74. En adelante citaré en el texto, señalando la página entre paréntesis. 
Emprende el viaje Eumenia, con la sola compañía de un criado, un viaje lleno de peligros y asechanzas, con el solo propósito de convencer a Alfonso de su error y así recuperar su felicidad inicial. Con esa única prueba enarbola la bandera de su verdad: no le importan los peligros de verse sola en un país extranjero si así recupera a su esposo ${ }^{31}$. En el caso de Alfonso, huye, engañado, de Madrid con el propósito inicial de separarse de Eumenia; pero una vez convencido de su error, decide convertir su errancia en penitencia, viviendo aislado del mundo en una ermita, con la sola esperanza de redimir sus culpas.

En el caso del joven francés que protagoniza Oderay, soldado del ejército colonial, su viaje a las tierras desconocidas de América del Norte se debe, en mi opinión, a un afán de medro, de conseguir en la carrera militar una fortuna que sabemos no posee, para casarse con su amada Eugenia, ya que, como él mismo afirma, su padre no veía con buenos ojos su enlace, porque «era pobre, no tenía bastante oro" (p. 159). Sin embargo, lejos de cumplirse esos objetivos iniciales, el viaje le servirá para su enriquecimiento moral, tras la elección que supone el conocimiento de Oderay y los hábitos de vida indios. De esta manera -oculta la trama novelesca tras el subtítulo original "Usos, trages, ritos, costumbres y leyes de los habitantes de la América septentrional", que lo convierte en un libro de viajes a los ojos de la censura-, por contraste con la sociedad occidental de la que procede el personaje, el texto se convierte en una dura crítica contra una civilización injusta que ha perdido los valores más auténticos del hombre ${ }^{32}$. No es un libro de viajes Oderay porque importa más la descripción de los sentimientos y de las costumbres indias que la de los paisajes y la narración exacta del movimiento a través de las diferentes comarcas que se atraviesan ${ }^{33}$.

En La Eumenia hallamos una historia secundaria muy curiosa, la del ermitaño Thibot, que el hermano Pablo narra a Amelo y

31 «La justificación de la acción corresponde a un motivo típico en la temática sentimental dieciochesca: la ruptura de un matrimonio por celos infundados de uno de los cónyuges, que huye mientras el otro mantiene intacto su amor y fidelidad y emprende un viaje sembrado de peripecias y destinado a unir a la pareja y disipar el equívoco» (GUILLERMO CARNERO, «Sensibilidad y exotismo en un novelista entre dos siglos: GASPAR ZAVALA Y ZAMORA», Canelobre, 10, 1987, p. 13).

32 Afirma Oderay: « ¿Tú, padre, dices que no consintió que Eugenia fuese tu esposa? ¿Luego en tu país no es el hombre libre para casarse con la muger que ama? ¿Luego puede alli un padre dexar abrasar de amores a su hija? ¡Oh, qué bien hiciste en venirte!» (p. 158); y más adelante: «Pues qué, ¿se come el oro en tu país? Bien me ha dicho mi padre que hay ciertos blancos tan avaros que abrasarian a otro hombre si creyesen hallar oro en sus cenizas. ¿Comes tú también oro, buen amigo? Mira, no tengo más que este anillo, tómale» (p. 159).

32 Vid., a modo de ejemplo, el viaje de Onteree al país de los chipeveses que han secuestrado a Oderay (pp. 184 y ss.). 
Eumenia mientras viajan para encontrar a Alfonso. Se trata de una peregrinación cristiana a Roma -como en el Persiles-, pero en este caso para redimir una culpa. El relato presenta todos los rasgos que, como veremos, caracterizan a la estructura bizantina: múltiples peripecias, cambio de vestidos, reconocimientos, final feliz y colofón moral. Se trata de un relato especular, metadiegético o en segundo grado, cuya relación con el relato principal es puramente temática (mise en abîme), ya que desarrolla una historia paralela a la de Alfonso. Su función en la novela es la de mostrar, con otra situación y otros personajes, el final y el sentido de esa historia ${ }^{34}$.

\section{IV}

Pese a conservar la estructura del viaje que caracterizaba a la novela bizantina, hemos visto cómo en las dos novelas de Zavala es muy diferente el sentido o la finalidad del mismo. No obstante, el motivo del viaje tendrá en ellas importantes implicaciones estructurales que convierten al novelista burgalés en deudor del esquema narrativo bizantino cuyo paradigma es Cervantes y que, como vimos más arriba, siguieron varios narradores dieciochescos.

No obstante, ambas novelas no se caracterizan precisamente por una gran movilidad accional o aventuresca. Más bien podemos hablar de una estructura dramática o teatral, perfectamente dispuesta y organizada en una concatenación de escenas - recordemos que Zavala era dramaturgo. "La acción de la novela debe mucho a la estructura de la comedia de enredo: dos damas, dos galanes y sus caminos cruzados" ${ }^{35}$. En términos narratológicos, la velocidad narrativa predominante en ambas novelas sería la escena -en la que prevalece el diálogo o el monólogo-, separadas unas de otras mediante rápidos sumarios de la historia o mediante pausas descriptivas - muy pocas; la mayoría de las descripciones están insertas en monólogos de los personajes- que jugarían la función de las acotaciones en las obras teatrales. Veámoslo en La Eumenia:

Libro I: 1. Monólogo inicial de Termonio. 2. Encuentro con Amelo. 3. Salvamento de Eumenia. 4. Eumenia en casa de Amelo: comienzo de su historia y reconocimiento.

34 Utilizo los términos de la nouvelle critique o escuela narratológica francesa, definidos por GÉRARD GÉNETTE en Figuras III (1972), Barcelona, Lumen, 1989. Sobre el relato especular o metadiegético, vid. pp. 287-289.

35 Álvarez BARRIENTOS, op. cit., p. 308. 
Libro II: 1. Muerte de Salmon. 2. Continuación de la historia de Eumenia. 3. Aparición de Florencia y Clara: reconocimiento y final feliz de la historia de Termonio.

Libro III: 1. Tres años transcurridos; Eumenia enferma. 2. Recepción de una carta de la hermana arrepentida y otra de Alfonso a la hermana. 3. Inicio del viaje de Amelo y Eumenia. 4. Relato especular del ermitaño Thibot. 5. Encuentro con la maestra: premoniciones.

Libro IV: 1. Hallazgo de la cabaña de salteadores. 2. Aparición del ermitaño Alfonso, salvamento y reconocimientos. 3. Vuelta a casa y final feliz.

Igualmente, para subrayar temáticamente la estructura del relato, Zavala comienza cada capítulo de su novela de 1805 con la exaltación de una virtud: en el Libro I, el amor a la patria; en el II, la esperanza; en el III, la amistad, y en el IV, la fe o las ilusiones del sueño. Como dice Guillermo Carnero de La Eumenia -y lo mismo puede afirmarse de Oderay-, «el hilo argumental es tenue; el acento no está puesto en aventuras o peripecias, que son las mínimas para dar pie a la exposición de sentimientos o reflexiones propias de la corriente sentimental de la épocan ${ }^{36}$.

Oderay es un relato autobiográfico en primera persona redactado en forma de carta que el narrador (Onteree) dirige a su amada (Eugenia), convertida de esta manera en narratario, pero que nunca recibirá ni leerá. Es la confesión epistolar de unos hechos acontecidos en un lugar remoto, desconocido y exótico, cuyo tiempo de la narración coincide con el de la historia ${ }^{37}$ :

Dos veces he visto cubiertos los árboles de flores y de frutos; dos veces fueron cubiertas de nieve esas montañas desde que dexé de trasladar al papel los tiernos sentimientos de mi corazon [...]. No me ha sido concedido escribir que te amo y que mi alma, semejante a la paloma que los niños ataron con un hilo, vuela a ti sin cesar para posar sobre tu seno, hasta que, cansada de bregar para romper el lazo que la detiene, cae en la noche de la muerte.

En este instante que me hallo sentado tranquilamente en mi pobre estera de palma, la mano acostumbrada a disparar una flecha, manejar un remo o enarbolar una hacha se ha endurecido de tal modo que apenas acierta a regir la pluma [...]. He olvidado casi del todo la lengua de mi pais; y aunque mi corazón desea hablarte en sus penas, tú no puedes ofrselas (pp. 137-138).

En las dos páginas que principian Oderay, Zavala nos da todas las premisas iniciales que necesitamos para situar el relato. Han

36 Op. cit., p. 11.

37 Alvarez BARRIEntos ya ha señalado que Oderay «tiene algo de novela epistolar» (op. cit., p. 307). 
transcurrido dos años desde que Onteree dejó de escribir, y en este mismo momento lo está haciendo. A la vez, el narrador-personaje nos habla de sí mismo, de sus sentimientos por Eugenia - la destinataria de esta carta-, de la joven que le ama pero que él no puede amar, y finalmente, de su lenta pero ya irrevocable mutación en uno más de los indios: ha adquirido sus costumbres, ha olvidado su lengua original... Incluso el estilo que emplea, lleno de referencias a la Naturaleza, es significante en esta mutación. Sólo queda, del hombre europeo que fue, su amor por Eugenia. Y continúa:

Una joven está sentada a par de mí, tan amable y bella como tú misma. El talento brilla en sus ojos y el fuego de la amistad hace palpitar su corazón. Sólo se complace en traerme cortezas blancas y exprimir en una concha el xugo de ciertas plantas para que pueda escribirte. Me ama con ternura, pero no puedo mirarla más que como a hermana, porque tú sola eres mi esposa [...]. Me hallo sentado, triste y en un continuo silencio; mis lágrimas caen sobre la corteza en que te escribo, y ni aun atiendo a las razones amistosas que me dice la joven que me acompaña.

Supremo Ser, que me apartaste de la muger que amaba, ya me resigno con tu voluntad sin proferir una queja; pero a lo menos guía Tú mi mano endurecida con el trabajo y haz que pueda yo escribir mi vida, porque vuele así mi alma a mi amada Eugenia (p. 138).

Ahora se pone de manifiesto su sensibilidad mediante las lágrimas, $\tan$ abundantes en la literatura dieciochesca, las cuales, "fueron también, como todo lo sensible, otra forma de acercarse al realismo, o de serlo ya. Llorar era una moda, una forma social de mostrar sensibilidad, pero en la literatura tenía, además, un sentido de intimidad erótica. La connotación de las lágrimas suele tener ese referente» ${ }^{38}$. Y termina nuestro héroe, antes de dar principio a su relato, con la invocación al Supremo Ser para que le ayude a escribir, siguiendo un viejo tópico clásico ${ }^{39}$.

El formato epistolar - que ya había utilizado Valladares de Sotomayor en La Leandra, como vimos- implicará a casi todas las instancias narrativas, pero contra lo que sería esperable, importa más - si atendemos a la extensión- los diálogos y monólogos que la narración de las peripecias, que son las mínimas para situar las premisas emocionales de los personajes. Por ello, y pese a su estructura novedosa, Oderay sigue debiendo mucho a los esquemas dramáticos zavalianos. Lo realmente importante es que el relato autobiográfico permite ahondar en el alma del personaje, descubriéndonos sus sentimientos, sus contradicciones y sus inquietudes,

38 Ibidem, pp. 394-395.

39 Vid. ERNST ROBERT CuRTIUS, Literatura euopea y Edad Media latina (1948), México, F.C.E., 1988, pp. 122-159. 
que pertenecen, a mi modo de ver, a una cosmovisión romántica o proto-romántica ${ }^{40}$.

Mis ideas eran agitadas como las aguas del lago, y mi corazón me decía: «Si no te desposas con la tierna Oderay, morirá como una flor abrasada por el sol; ella te dio la vida, ¿y tendrás valor para dexarla morir?» Su penetrante voz resonaba en lo interior del alma, explicándome sus penas. También óla tu voz, oh Eugenia: «iAy!, séme fiel, me decías, que quizá la suerte te acercará a mí un día; y si te ves unido a Oderay, entonces ella y sus hijos formarán al rededor de ti una fuerte cadena; tú no podrás romperla, y tu Eugenia, la amiga de tu infancia, que aún arde en aquel amor que formaba la felicidad de tus primeros años y la desgracia de su vida, morirá al exceso de su dolor» (p. 217).

En muchos de estos momentos, como ya anuncié más arriba, el texto se abre hacia lo lírico, como en esta última declaración de Oderay antes de morir:

...Mi alma volará siempre en torno de vosotros, si vais a los bosques oiréis sus sollozos entre el murmullo de los vientos; si en medio de la noche os veis asaltados de melancólicas ideas, oiréis su voz fugitiva como el eco; ella se mezclará en los cánticos de muerte de las jóvenes que lloren sobre mi tumba, y quando fuereis vosotros durante la noche a ofrecerme vuestras lágrimas, ella hará estremecer vuestros corazones. Y tú, pobre, buen amigo, arderás en amor por Oderay quando ya no existirá, y conocerás la fuerza de mi pasión quando ya no pueda hacerte feliz (p. 239).

Los modelos narrativos que sigue Zavala en sus dos novelas no sólo obedecerán, como pretendo demostrar, al menos en parte, a la estructura bizantina. La estructura dramática y la epistolar son las más evidentes, pero como vamos a ver a continuación, una serie de rasgos que caracterizan al género bizantino, se repiten o se recrean en La Eumenia y en Oderay.

\section{V}

Como sucede en todos los géneros narrativos de la Edad de Oro, se hace imprescindible hablar en el escritor prerromántico, como apunté más arriba, de una conciencia de género, de una voluntad de inscribir a su obra en una tradición, de situarse en la estela en unos modelos determinados mediante la imitación. Dejando aparte

40 Álvarez BaRrientos subraya el empleo del monólogo en la narrativa dieciochesca «como expresión del análisis de los sentimientos», sirviéndose del medio de la carta, con el modelo de la Pamela de RICHARDSON («Algunas ideas sobre teoría de la novela en el siglo XVIII en Inglaterra y en Españax, Anales de Literatura Española, 2, 1983, p. 13). 
la cuestión de la estructura dramática y de la novela epistolar, me centraré a continuación en los rasgos estructurales que configuran el modelo bizantino, y que arrancan en la literatura española del Persiles de Cervantes y de $E l$ peregrino en su patria de Lope ${ }^{41}$. Algunos elementos de La Eumenia y de Oderay, como veremos, se apoyan en una serie de componentes de marcado origen bizantino, y su presencia explícita ayuda al lector a reconocerlas dentro del modelo narrativo de amor y de aventuras, si bien, como ya he dicho, el escritor burgalés enriquece $y$, en cierta medida, supera ese corsé genérico. Los más importantes de esos elementos bizantinos pertenecen al dominio de la estructura narrativa, del desarrollo de la acción.

En primer lugar, la complicación del asunto, es decir, el trazado de unas historias secundarias que fluyen paralelas a la historia principal. Si las historias principales narradas en La Eumenia y Oderay son básicamente de tipo amoroso (Eumenia y Alfonso, Onteree y Oderay), también lo son las historias secundarias, de desarrollo necesariamente más modesto (Termonio y Clara, Onteree y Eugenia, Omourayoo y Omayra), que se convierten de esta manera en correlatos temáticos de la historia principal, aquélla en la que el lector centra su atención. De forma paralela, el narrador esboza los elementos básicos de la historia secundaria, y su desenlace llega antes que la de la principal: el final feliz de aquella anticipa el de ésta. Era ésta una cualidad del Persiles -imitación de la Historia etiópica de Heliodoro- que aplaude Mayans y Siscar en su Vida de Miguel de Cervantes:

Los trabajos de Persiles y Sigismunda son una clara imitación de la Ulisea de Homero i Ethiópica de Heliodoro, con quien Cervantes intentó competir i en mi juicio le huviera aventajado si, con la fecundidad de su ingenio, no huviera entremezclado tantos episodios que desfiguran $i$ desaparecen la constitución i proporción de los miembros de la fábula principal. Pero este mismo descuido tiene una singular prerrogativa, $i$ es que muchos destos episodios son otras tantas tragedias donde la acción es una i de persona ilustre i el estilo correspondiente a la grandeza de la acción, sin que falte otra cosa para la composición de una perfecta tragedia sino la disposición dramática, coro i aparato sénico ${ }^{42}$.

Además de poner en relación el Persiles con el género de la tragedia, por la gravedad del estilo y del asunto y por la disposición de las escenas - de manera análoga a como hace Zavala, como

41 Para los elementos configuradores del modelo bizantino, sigo a LOPEZ ESTRADA (op. cit., pp. xlvi-xlix), y principalmente a MIGUEL ÁNGEL TEIJEIRO FUENTES ( «Jerónimo de Contreras y los nueve libros de la Selva de aventuras. Aproximación al modelo bizantino», Anuario de Estudios Filologicos, 10, 1987, pp. 345-359).

42 Ed. cit., pp. 150-151. 
hemos visto-, subraya Mayans el hecho de la complicación del asunto, el enriquecimiento de la acción principal con otras secundarias. Y además, cabe apostillar que uno de los motivos de que el novelista complique la acción - junto al afán moralizador- se debe a la voluntad de mantener el interés del público, de ofrecer historias paralelas, a modo de micronovelas especulares, para deleitar el placer de la ficción, el gusto por la aventura, ya que el lector siempre acogerá mejor una enseñanza novelada que una «instrucción seca y áridamente propuesta», en palabras de Martínez Colomer ${ }^{43}$. No hay que olvidar, a este propósito, el sentido de la parodia cervantina en el Quijote o la moratiniana en La comedia nueva, contra las comedias de capa y espada ${ }^{44}$.

Elementos clave del modelo bizantino son la anagnórisis o reconocimiento y el final feliz de la historia, como premio o recompensa por los trabajos sufridos. La sucesión de peripecias provoca las separaciones de los amantes, los padres de los hijos..., que permanecen años y años sin verse. Así sucede en La Eumenia, no sólo con la historia principal (Eumenia y Amelo reencuentran a su esposo e hijo), sino también con las secundarias (Termonio y Clara, la historia de Thibot). Además, en esta novela la anagnórisis sirve de motivo estructural al cerrar cada uno de los cuatro capítulos. Se trata de un procedimiento narrativo que persigue mantener viva la tensión dramática hasta el fin. Relacionado con la anagnórisis está el recurso de la mentira y el del trueque de vestidos (Alfonso desfiguado y convertido en un homo selvaticus) que también hallamos en Oderay (Onteree convertido en un indio), y que dificultan el reconocimiento, añadiendo a la historia una mayor tensión dramática. Lo que sucede en Oderay es la separación de los amantes (Onteree y Eugenia), pero para no reunirse jamás; es decir, Zavala emplea el motivo pero no el reconocimiento ni el final feliz de la historia, para hacer de lo que parecía un libro de viajes una gran tragedia romántica.

Una gran innovación estructural, en el campo del tratamiento del tiempo, que introduce el modelo bizantino de amor y de aventu-

${ }^{43}$ El Valdemaro, ed. cit., p. 51.

44 Pero el novelista complutense no rechaza el uso de lo aventuresco, y su transformación ideológica y estética se concretará de forma espléndida en el Persiles: «con todo cuanto mal había dicho de tales libros [de caballerías], hallaba en ellos una cosa buena: que era el sujeto que ofrecían para que un buen entendimiento pudiese mostrarse en ellos, porque daban largo y espacioso campo por donde sin empacho alguno pudiese correr la pluma, describiendo naufragios, tormentas, rencuentros y batallas», «y siendo esto hecho con apacibilidad de estilo y con ingeniosa invención, que tire lo más que fuere posible a la verdad, sin duda compondrá una tela de varios y hermosos nudos tejida, que después de acabada, tal perfección y hermosura muestre, que consiga el fin mejor que se pretende en los escritos, que es ensefiar y deleitar juntamente» (Quijote, ed. cit., I, pp. 603 y 604). 
ras es el comienzo de la historia in medias res, es decir, tomando la historia por el medio, no por el principio. Ello implica que los personajes se conviertan así en los narradores de su propia historia pasada, con el fin de que el lector la reconstruya, y que amplios pasajes de la novela sean analepsis retrospectivas completivas, en términos narratológicos ${ }^{45}$. Así, nada más comenzar La Eumenia, Termonio recuerda su pasado tormentoso (pp. 63-64); Amelo explica la historia de Alfonso (pp. 68-69); Eumenia la suya (pp. 75-76 y 82-90) y Alfonso la suya (pp. 125-126), con lo cual nos es dado conocer toda la amplitud de la historia y completar los datos que faltaban para la comprensión del final. El narrador-personaje de Oderay, Onteree, también dedica mucho espacio en su confesión epistolar al relato de los hechos acontecidos entre el comienzo del mismo (cuando ya ha conocido a Oderay), el tiempo de la narración y el comienzo de la historia, cuando, todavía soldado francés, se trasladó a América del Norte.

Hemos de tener en cuenta que el modelo bizantino europeo, basado en la imitación de Heliodoro, introdujo todos estos cambios en la novela y muy tempranamente pasaron a impregnar otros géneros narrativos. Ello permite afirmar a López Estrada que "principio, desarrollo y fin supusieron, pues, un modelo para los relatos de ficción en cuanto a técnica narrativa" ${ }^{46}$.

Otros motivos presentes en las dos novelas de Zavala son también característicos del modelo bizantino. Así, las lamentaciones y lloros con que los personajes sensibles acompañan sus largos parlamentos, sean en diálogo o en monólogo; pero a las alturas de 1780 este motivo se ve impregnado de la influencia del sensismo y el naciente Romanticismo. Lo ha señalado Valentina de Antonio Domínguez a propósito de los dramas sentimentales de Zavala: «el comienzo de esta nueva sensibilidad conduce asimismo a un concepto nuevo de lo poético, donde se daba la exigencia imperativa de conmover, trastornar y desgarrar los corazones" ${ }^{47}$. También era un componente básico de la novela bizantina «la presencia de fuerzas sobrenaturales que continuamente están condicionando el comportamiento de los personajes" ${ }^{48}$, que reciben una denominación más acorde con el propósito moralizante de la aventura: Fortuna, Destino, Providencia, Dios en el Persiles de Cervantes; en Oderay, de acuerdo con el deísmo ilustrado - pero también con el panté́smo de los indios-, Ser Supremo. Los designios de estas fuerzas sobre-

45 Vid. GENETTE, op. cit., pp. 91-120.

46 Op. cit., p. xlix.

47 «Horizonte de expectativas y tematismos secundarios: Zavala y Zamora en la génesis romántica», Barcarola, 47-48, 1995, p. 171.

48 TEIJEIRO FUENTES, op. cit., p. 355. 
naturales, que imponen duros trabajos a los personajes, son aceptados estoicamente, con resignación y confianza, y su superación significa el final feliz que tienen estas novelas. Esta voluntad divina ilumina en ocasiones a los personajes y les informa acerca de cómo deben actuar a través de los sueños premonitorios, o bien les anuncia el final feliz de sus infortunios: se trata de un motivo de raíz bíblica que pasará a la novela bizantina.

Sin embargo, esa actitud estoica a la que deben agarrarse los personajes para no caer en la desesperación o el vacío me parece clave en el tránsito hacia el héroe romántico. Todos los personajes de La Eumenia "convinieron al fin que la voluntad de la Providencia era el principio consolador a quien debía atribuirse quanto sucediera» (p. 128). Parece como si Zavala pretendiera reprender la desesperación a la que se entrega, hastiado y atormentado, el héroe romántico que lentamente empieza a emerger en estas obras del cambio de siglo, brindando como escudo frente al "fastidio universal» 49 el "principio consolador» de la Providencia divina. En este sentido cabe entender el final de Oderay, con el suicidio de la joven india. Los consejos finales del anciano sabio a Onteree vienen a ser, en este sentido, el colofón moral de la novela: «Espéralo todo del Supremo Ser, que es quien hace descender el consuelo hasta la tienda de la muerte del miserable cautivo; él destina a cada situación los placeres que la son debidos" (p. 264).

\author{
DAVID ORDÓNEZZ GARCIA \\ Universidad de Barcelona
}

49 Ha rastreado la aparición y fortuna del término y su presencia en los escritores dieciochescos y románticos RUSSELL P. SEBOLD, «Sobre el nombre español del dolor romántico» (1968), en El rapto de la mente. Poética y poesía dieciochescas (1970), Barcelona, Anthropos, 1989, 2.* ed., pp. 157-169. 